\title{
Adoption of Sustainable Construction in the Malaysian Residential Construction Sector: A Conceptual Framework
}

\author{
Noorsaidi Mahat ${ }^{1,2}$, Joseph H.M. Tah ${ }^{1}$ and Christos Vidalakis ${ }^{1}$
}

\begin{abstract}
The adoption and implementation of Sustainable Construction has been one of the main challenges facing the construction industry for the last three decades. The issue has attracted global attention with many governments and organizations developing codes and frameworks to encourage and enforce the adoption of Sustainable Construction. However, current evidence suggests that companies and individuals are struggling to commit to Sustainable Construction and implement the suggested policies. To address this problem, the study aims to investigate the adoption of Sustainable Construction in the Malaysian residential construction sector. The Innovations Diffusion Theory (IDT) and the Theory of Planned Behavior (TPB) are utilized as a theoretical basis for developing a better understanding and explaining the reasons behind the adoption of Sustainable Construction. The combination of components from both theories results in the development of a conceptual framework that identifies the factors affecting the individual's decision making process and facilitates understanding of the decision to adopt Sustainable Construction.
\end{abstract}

Keywords - Sustainable construction, diffusion of innovations, theory of planned behaviour.

\section{INTRODUCTION}

Residential buildings are one of the largest consumers of energy and water as well as producers of emissions and waste. During operation they consumes $32 \%$ of the world's renewable and non-renewable resources, $12 \%$ of available water and $40 \%$ of produced energy, while generating $40 \%$ of global $\mathrm{CO} 2$ emissions [1]. Apart from the potential to improve the environmental performance of buildings, Sustainable Construction (SC) has been associated with numerous benefits including increased property value, improved occupant productivity and better corporate image [2]. However, Even though SC seems to be an attractive business proposition for housing developers, adoption has been slow. Indeed, as pointed out by [3] delivering sustainability remains a challenge partly due to a range of traditional, cultural and structural barriers such as the lack of integration between the different project stages, poor collaboration between the various professions in the project team and lowest-cost focused procurement [4],[5],[6]. The latter, i.e. cost concerns have been cited by many researchers as the most important barrier

\footnotetext{
${ }^{1}$ School of the Built Environment, Faculty of Technology, Design and Environment, Oxford Brookes University, Oxford

${ }^{2}$ Faculty of Architecture, Planning and Surveying, Universiti Teknologi MARA Sarawak, Kota Samarahan, Sarawak, Malaysia.
}

to sustainable construction [4],[5],[7].

To encourage and enforce the adoption of SC many governments and organizations across the globe have proposed and implemented a series of measures and strategies. Malaysia has one of the best set of environmental legislations, comparable even with those of developed countries [8], indeed, a number of sustainable development frameworks and policies are in place, deployed to reduce and overcome sustainability issues. However, current evidence suggests that companies and individuals are struggling to commit to SC. As shown by [9-14], the level of knowledge and awareness of environment issues and sustainability aspects among Malaysian residential developers has been particularly low [914]. This indicates that the concerted efforts for promoting SC have not had the anticipated impact.

The majority of the studies looking at SC adoption have focused on design for sustainability [15], sustainability performance [16] and sustainability related technological challenges [17]. Very little emphasis has been place on the people dimension. A very small number of recent studies have investigated the people-related challenges in SC adoption [18],[19],[20]. This is rather paradoxical given that the decision to implement SC is ultimately made by individuals and influenced by factors which have been largely overlooked by the main body of SC literature [19]. It is evident that further research is required into the factors affecting the decision of residential developers to embrace SC in the context of Malaysia. Therefore, this study explores the residential building developers point of views by looking at the decision making process resulting in the adoption of SC. This is achieved by utilizing the theories of Innovations Diffusion (IDT) and Planned Behavior (TPB) as a theoretical basis to explain the reasons behind the adoption of SC. The combination of components from both theories results in the development of a conceptual framework that identifies the factors affecting the individual's decision making process and facilitates understanding of the decision to adopt SC.

\section{SUSTAINABLE CONSTRUCTION}

\section{A. Sustainable Construction as an Innovation}

Innovation is an idea, practice, or object that is perceived as new by an individual or other unit of adoption [20]. SC, as a concept, was introduced in the 80s; however, new materials, requirements and approaches are constantly developed and 
introduced. For example, in 2013 the introduction of sustainability checkpoints into RIBA plan of work had a major impact on the RIBA update of the construction project development model. Indeed, the definition of innovation [21] includes not only products and services which are new but refers to pre-existing approaches that are recently amended and often, are perceived as new. According to Froese and Rankin [22], an innovation is the mechanism at the centre of the key strategic goal of continuous development. This is in line with [23]'s suggestion that SC defines a new business model for construction companies that can result in competitive advantage by responding to the social demand for sustainability. Therefore, the concept of SC is which is expected to have a major impact on existing norms and therefore can be viewed as an innovation.

\section{B. Sustainable Construction adoption as a Behaviour}

It is widely acknowledged that the construction industry is slow at adopting SC as a new concept or practice [9-14]. Before a business can make a decision whether to adopt a new concept or practice, it must first to evaluate the benefits it will gain and compare them to the costs and risks involved [24]. Benefits refer to the relative advantages the innovation can provide to the business while costs/risks include incompatibility with existing behaviour and values, the difficulty of use, unavailability of a trial, and the lack of a visible effect on the business [27]. In fact, cost is one of the key criteria in making decisions over whether or not to adopt a new practice or concept [26]. Making an intention to adopt SC as an innovation is made through a cost-benefit analysis in an uncertain environment.

\section{THEORETICAL BASIS OF THE RESEARCH}

This paper proposes a conceptual framework for understanding the different degrees of implementation of SC. This work explicitly draws upon two distinct yet theoretically related bodies of research. The first is research into the diffusion of innovations [23], which in general investigates individuals' reactions to new products or processes. The second is research on the Theory of Planned Behaviour [33] which is a general theory applicable to an array of behaviors, including the forces which influence the implementation of SC. Diffusion research applies to the behavior of accepting or rejecting an innovation. Thus, to the extent that personal implementation of SC can be considered as an innovation, certain concepts of diffusion research could be used to apply the Theory of Planned Behaviour to SC implementation. In this study the generic perceptions of adopting a product or service are used to serve as the beliefs used in the Theory of Planned Behaviour.

\section{A. Innovations Diffusion Theory (IDT)}

Diffusion is the process by which an innovation is communicated through certain channels over time among the members of a social system. Supposing that the decision to adopt (an innovation) is authoritative or collective, the innovation decision by members of a social system is made through four stages [27]. Knowledge is the first stage, in which members of the social system start to get an idea about the innovation and how it functions. Persuasion is the second stage, in which they form an attitude (favourable or not) towards the innovation. Deciding to adopt or not to adopt is the third stage, 'decision'. Implementing the innovation occurs in the fourth stage, 'confirmation', in which users also evaluate the innovation based on the decision they have made (refer Fig. 1.

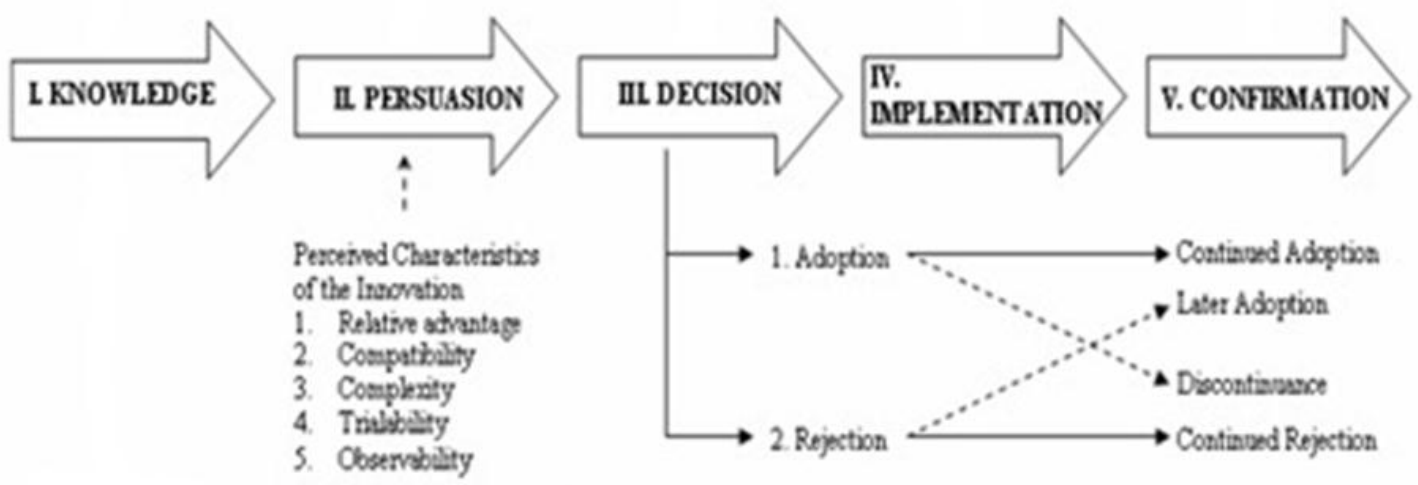

Fig. 1 A Model of Five Stages in the Innovation-Decision Process. Source: Everett M. Rogers'. Diffusion of Innovations, Fifth Edition. Copyright (c) 2003 by The Free Press.

\section{B. Theory of Planned Behaviour (TPB)}

The TPB (refer Fig. 2) is an extension of the Theory of the Reason Action (TRA), aimed at addressing its limitations. In addition to an individual's attitude towards performing the behaviour, and their subjective norms, from TRA, TPB also includes the perceived behavioural control construct. Perceived behavioural control is the individual's belief about how easy or difficult it will be to perform the behaviour [28].
Recently, [29] added different combinations of antecedents to the original constructs of the theory [29], namely, behavioural beliefs (beliefs about the behaviour), normative beliefs (beliefs about what others think about the behaviour), and control beliefs (beliefs about one's level of control over one's behaviour). Actual behavioural control is another determinant of behaviour and refers to the individual's control over behavioural factors such as resources (e.g. money, time, skills) or the cooperation of others. 


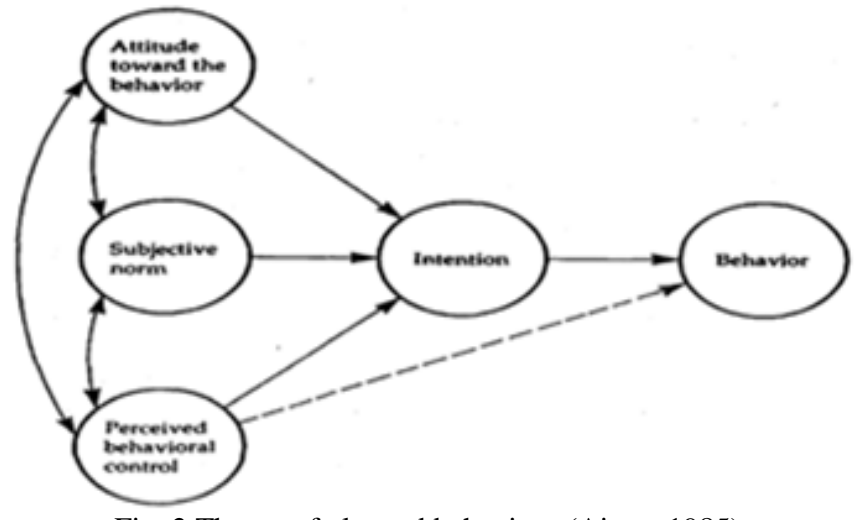

Fig. 2 Theory of planned behaviour.(Ajzen, 1985)

Although adding perceived behavioural control enhances the prediction of actual behaviour in TPB, the diversity of labels and operational definitions of this construct used in empirical research means that it is still controversial, and there are doubts over the ability to discriminate between perceived behaviour control and intentions [30]. Additionally, the predictability of intention is expected to vary across behaviours and situations, and in institutions where attitude is strong and subjective norms are powerful, perceived behavioural control would be less predictive of intention [31].

\section{THE CONCEPTUAL FRAMEWORK}

This research utilises diffusion research theory to provide a basis for identifying a set of generic perceptions or beliefs which could affect one's attitude towards implementation SC. It then integrates these perceptions with several constructs from the TPB to develop a framework which helps explain individual adoption of SC (Refer Fig.3). According to diffusion theory, there are a variety of factors that can be identified as affecting the formation of one's attitude and subjective norms, such as the communication network of an individual. The components of the conceptual framework shown in Figure 3 are described as below;

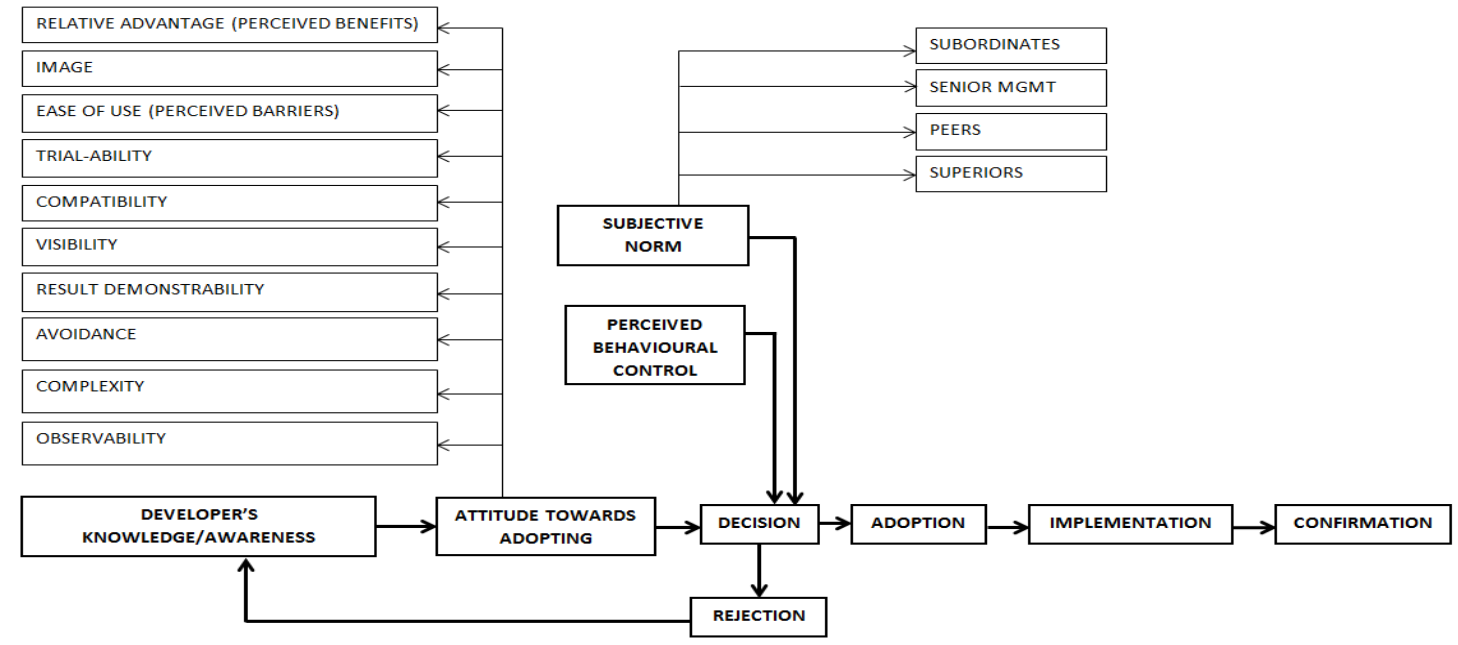

Fig. 3 A conceptual framework for sustainable construction adoption in residential construction sector (Source; adapted from Rogers' innovation diffusion theory (IDT) and Ajzen theory of planned behaviour (TPB).

\section{A. Adoption}

Sustainable Construction (SC) adoption in residential building projects is the behaviour of interest and hence is the dependent variable in this study.

\section{B. Attitude towards adopting}

In this study, the focus will be on the cognitive aspects, or perceptions, that a person has towards performing a behavior. In diffusion theory, the perceptions which are hypothesized to have an effect on attitude have been cast as the perceived characteristics of innovations, and have been shown in a number of studies to be linked to adoption/rejection decisions. Compatibility, relative advantage, and complexity were consistently associated with innovative behaviors [32]. Rogers had earlier identified these three characteristics, as well as trialability and observability [23]. Because of the popularity of Rogers' work, which has become one of the most cited works in the social sciences, five characteristics will be included in the study. Finally, a sixth characteristic, image, was also included since Rogers had indicated that although image might be subsumed under relative advantage, in some instances it was a motivating factor on its own. The next stage was to develop an instrument to measure these various characteristics. In the instrument development process, observability will be tap into two different constructs, result demonstrability and visibility, and thus was split. As a result, seven perceived characteristics of SC adoption in residential building projects will be eventually included in the study, i.e. Relative advantage (perceived benefits), compatibility, ease of use (perceived barriers), trialability, image, result demonstrability, and visibility.

\section{Subjective norm}

One of the potential determinants of behavior is the Subjective Norm (SN). SN is formed from one's motivation to comply with what one believes others expect one to do. Several individuals may serve as potential "referents" influencing one's behavior with respect to SC adoption in 
RBP. These could include senior management, superiors, subordinates and peers.

\section{Perceived behavioural Control}

Perceived behavioural control is the individual's belief about how easy or difficult it will be to perform the behaviour, whereas SN refers to the perceived social pressure to perform a certain behavior [29]. SN sets an informal requirement; it is up to the individual to conform with the expectations of others or not.

\section{E. Behaviour}

Behavioral intention is not included in the conceptual framework. If no other variables intervened once an attitude and subjective norms were formed, or if the behavior was to be performed immediately, then intention could be dropped from the conceptual framework without a loss of information. Intentions are used to predict behavior, and therefore to be of value "it is important to measure [them] as close as possible to the behavioral observation" [33]. Indeed, in this study, the aim is not to predict future behavior; rather, to determine how current behavior is related to subjective norm and attitude.

\section{V.CONCLUSION}

In conclusion, this study suggested a conceptual framework for understanding the different degrees of implementation of SC by individuals. This work explicitly draws upon two distinct yet theoretically related bodies of research. The first is research into the diffusion of innovations, which in general investigates individuals' reactions to new products or processes. The second is research on the Theory of Planned Behaviour which is a general theory applicable to an array of behaviors, including the forces which influence the implementation of SC. Past research highlights the need to further research for sustainable construction adoption frameworks into the factors affecting sustainable construction adoption in the Malaysian residential construction sector. The conceptual framework presented in this paper was based on a review of the literature and need to be futher investigated and validated through rimary research which is in the next phases of the study.

\section{ACKNOWLEDGMENT}

This work is supported by the Malaysian government through the SLAB/SLAI scholarship and Oxford Brookes University, Oxford.

\section{REFERENCES}

[1] GBCA (2013) 'Green Star project directory', Available from: Green Building Council Australia. Accessed.

[2] Hyland, M., Lyons, R. C. and Lyons, S. (2013) 'The value of domestic building energy efficiency — evidence from Ireland', Energy Economics, 40 , pp. 943-952.

https://doi.org/10.1016/j.eneco.2013.07.020

[3] Thomson, C. S., El-Haram, M., Egbu, C. and Lou, E. 'Exploring the potential of sustainability action plans within construction projects'. Proceedings 27th Annual ARCOM Conference, Association of Researchers in Construction Management, Bristol, 5-7.
[4] Sodagar, B. and Fieldson, R. (2008) 'Towards a low carbon construction practice', Construction information quarterly, 10(3), pp. 101-108.

[5] Häkkinen, T. and Belloni, K. (2011) 'Barriers and drivers for sustainable building', Building Research \& Information, 39(3), pp. 239-255. 13 Abidin, N. Z. (2010) 'Investigating the awareness and application of sustainable construction concept by Malaysian developers', Habitat International, 34(4), pp. 421-426

https://doi.org/10.1016/j.habitatint.2009.11.011

[6] Razali, M. N. and Mohd Adnan, Y. (2015) 'Sustainable property development by Malaysian property companies', Property Management, 33(5), pp. 451-477.

https://doi.org/10.1108/PM-02-2014-0008

[7] Adetunji, I., Price, A., Fleming, P. and Kemp, P. (2003) 'Sustainability and the UK construction industry - a review'. Proceedings of the Institution of Civil Engineers-Engineering Sustainability: Thomas Telford Ltd, 185-199.

https://doi.org/10.1680/ensu.2003.156.4.185

[8] Sani, S. and Mohd Sham, A. (2007) 'Environmental management in Malaysia: Changing concerns and approaches', IMPAK, 3, pp. 4-6.

[9] Haron, S. A., Paim, L. and Yahaya, N. (2005) 'Towards sustainable consumption: an examination of environmental knowledge among Malaysians', International Journal of Consumer Studies, 29(5), pp. 426436.

https://doi.org/10.1111/j.1470-6431.2005.00460.x

[10] CIDB (2007) 'Construction Industry Master Plan Malaysia 2006-2015', Kuala Lumpur. Construction Industry Development Board Malaysia.

[11] Abidin, N. Z. (2010) 'Investigating the awareness and application of sustainable construction concept by Malaysian developers', Habitat International, 34(4), pp. 421-426.

https://doi.org/10.1016/j.habitatint.2009.11.011

[12] Elias, E. M. and Lin, C. K. (2015) 'The empirical study of green buildings (residential) implementation: perspective of house developers', Procedia Environmental Sciences, 28, pp. 708-716.

https://doi.org/10.1016/j.proenv.2015.07.083

[13] Idris, N. H., Ismail, Z. and Hashim, H. (2015) 'Towards a Framework for Promoting Sustainable Construction in Malaysia', Jurnal Teknologi, $76(1)$.

[14] Sieffert, Y., Huygen, J. and Daudon, D. (2014) 'Sustainable construction with repurposed materials in the context of a civil engineeringarchitecture collaboration', Journal of Cleaner Production, 67, pp. 125138.

ttps://doi.org/10.1016/j.jclepro.2013.12.018

[15] Nilashi, M., Zakaria, R., Ibrahim, O., Majid, M. Z. A., Zin, R. M., Chugtai, M. W., Abidin, N. I. Z., Sahamir, S. R. and Yakubu, D. A. (2015) 'A knowledge-based expert system for assessing the performance level of green buildings', Knowledge-Based Systems, 86, pp. 194-209. https://doi.org/10.1016/j.knosys.2015.06.009

[16] Sim, Y. L. and Putuhena, F. J. (2015) 'Green building technology initiatives to achieve construction quality and environmental sustainability in the construction industry in Malaysia', Management of Environmental Quality: An International Journal, 26(2), pp. 233-249. https://doi.org/10.1108/MEQ-08-2013-0093

[17] Diyana, A. N. and Abidin, N. Z. (2013) 'Motivation and Expectation of Developers on Green Construction: A Conceptual View'. Proceedings of World Academy of Science, Engineering and Technology, 2013: World Academy of Science, Engineering and Technology (WASET), 247.

[18] Joachim, O. I., Kamarudin, N., Aliagha, G. U. and Ufere, K. J. (2015) 'Theoretical Explanations of Environmental Motivations and Expectations of Clients on Green Building Demand and Investment'. IOP Conference Series: Earth and Environmental Science, 2015: IOP Publishing, 012010 https://doi.org/10.1088/1755-1315/23/1/012010

[19] Abidin, N. Z. and Afandi, N. D. (2015) 'Exploring developers' expectation on green construction', Advances in Environmental Biology, pp. 75-79.

[20] Rogers, E., M (2003) 'Diffusion of Innovations', The Free Press.

[21] Sahin, I. (2006). Detailed review of Rogers' diffusion of innovations theory and educational technology-related studies based on Rogers' 
theory. TOJET: The Turkish Online Journal of Educational

Technology, 5(2).

[22] Froese, T., \& Rankin, J. (2011). Strategic roadmaps for construction innovation: assessing the state of research (Doctoral dissertation, University of British Columbia).

[23] Rogers, E., M (1995) Diffusion of Innovations. New York: The Free Press.

[24] Nemoto, M. C. M. O., Vasconcellos, E. P. G. d. and Nelson, R. (2010) 'The adoption of new technology: conceptual model and application', Journal of technology management \& innovation, 5(4), pp. 95-107. https://doi.org/10.4067/S0718-27242010000400008

[25] Hall, B. H. and Khan, B. (2003) 'Adoption of new technology': National bureau of economic research.

[26] Sieber, S. and Valor, J. (2008) 'Criteria for adopting information and communication technologies', PELLICER, M.(ed.).

[27] 28 Rogers, E., M (1995) Diffusion of Innovations. New York: The Free Press.

[28] Ajzen, I. (1991) 'The theory of planned behavior', Organizational behavior and human decision processes, 50(2), pp. 179-211.

https://doi.org/10.1016/0749-5978(91)90020-T

[29] Ajzen, I. (2006) 'The theory of planned behavior', Organizational behavior and human decision processes, 50(2), pp. 179-211. https://doi.org/10.1016/0749-5978(91)90020-T

[30] Kraft, P., Rise, J., Sutton, S., \& Røysamb, E. (2005). Perceived difficulty in the theory of planned behaviour: Perceived behavioural control or affective attitude?. British Journal of Social Psychology, 44(3), 479-496.

https://doi.org/10.1348/014466604X17533

[31] Armitage, C. J., \& Conner, M. (2001). Efficacy of the theory of planned behaviour: A meta-analytic review. British journal of social psychology,40(4), 471-499.

https://doi.org/10.1348/014466601164939

[32] Tornatzky, L. G., \& Klein, K. J. (1982). Innovation characteristics and innovation adoption-implementation: A meta-analysis of findings. IEEE Transactions on engineering management, (1), 28-45.

https://doi.org/10.1109/TEM.1982.6447463

[33] Ajzen, I., \& Fishbein, M. (1980). Understanding attitudes and predicting social behaviour 